\title{
A novel anti-virulence gene revealed by proteomic analysis in Shigella flexneri 2 a
}

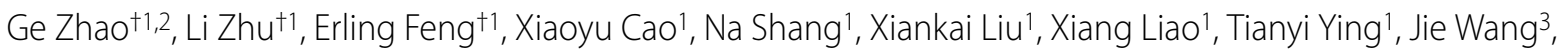 \\ Huipeng Chen ${ }^{1}$ and Hengliang Wang ${ }^{* 1}$
}

\begin{abstract}
Background: Shigella flexneri is a gram-negative, facultative pathogen that causes the majority of communicable bacterial dysenteries in developing countries. The virulence factors of $S$. flexneri have been shown to be produced at 37 degrees $C$ but not at 30 degrees $C$. To discover potential, novel virulence-related proteins of $S$. flexneri, we performed differential in-gel electrophoresis (DIGE) analysis to measure changes in the expression profile that are induced by a temperature increase.

Results: The ArgT protein was dramatically down-regulated at 37 degrees C. In contrast, the ArgT from the nonpathogenic E. coli did not show this differential expression as in S. flexneri, which suggested that argT might be a potential anti-virulence gene. Competitive invasion assays in HeLa cells and in BALB/c mice with argT mutants were

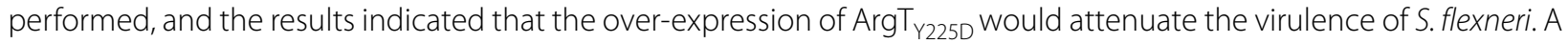
comparative proteomic analysis was subsequently performed to investigate the effects of ArgT in S. flexneri at the molecular level. We show that HtrA is differentially expressed among different derivative strains.

Conclusion: Gene argT is a novel anti-virulence gene that may interfere with the virulence of S. flexneri via the transport of specific amino acids or by affecting the expression of the virulence factor, $\mathrm{HtrA}$.
\end{abstract}

\section{Background}

Shigella flexneri is a gram-negative, facultative pathogen that is the leading cause of communicable bacterial dysenteries in developing countries. The virulence genes of S. flexneri are located on a large plasmid that was acquired by horizontal gene transfer. These genes encode a type III secretion system (TTSS) apparatus that enables S. flexneri to invade epithelial cells in the lower gut of humans [1].

The expression of virulence genes is induced under growth conditions similar to those found at the site of invasion. For example, a temperature of $37^{\circ} \mathrm{C}$ is a particularly important environmental signal. Maurelli et al. [2] found that $S$. flexneri cultivated at $37^{\circ} \mathrm{C}$ produced keratoconjunctivitis in guinea pigs and were able to penetrate and replicate in intestinal epithelial cells, but that bacteria grown at $30^{\circ} \mathrm{C}$ were phenotypically avirulent and nonin-

*Correspondence: wanghl@nic.bmi.ac.cn

1 Beijing Institute of Biotechnology, State Key Laboratory of Pathogen and

Biosecurity, Beijing 100071, China

+ Contributed equally

Full list of author information is available at the end of the article vasive. Other studies in S. flexneri have focused on regulation of the expression of these virulence genes at different temperatures $[1,3]$. However, we expected that, in addition to known virulence genes, a large number of other genes would be differentially expressed in response to a change in environmental temperature. To obtain a global view of the expression-level response of S. flexneri induced by a temperature increase and to find potentially novel virulence-related proteins, we performed a comparative proteomic analysis using the differential in-gel electrophoresis (DIGE) technique and mass spectrometry. Interestingly, the abundance of protein ArgT was dramatically decreased at $37^{\circ} \mathrm{C}$.

The evolution of bacterial pathogens from nonpathogenic ancestors is marked principally by the acquisition of virulence gene clusters on plasmids and pathogenicity islands via horizontal gene transfer [4]. Genes that are no longer compatible with the novel lifestyle of the pathogen are selectively inactivated either by point mutation, insertion, or deletion. These incompatible genes are defined as anti-virulence genes [5]. At present, several anti-viru- 
lence genes, such as $c a d A, o m p T$, nad $A$ and $n a d B$, have been identified in $S$. flexneri $[5,6]$. In our previous report [7], we have showed that protein ArgT is degraded by $\mathrm{Htr}$ A protease in S. flexneri grown at $37^{\circ} \mathrm{C}$. This finding is validated by this paper using a different proteomic method (DIGE). ArgT, a lysine/arginine/ornithine-binding protein ( $\mathrm{LAO})$, localizes in the periplasmic space and is responsible for binding the amino acid substrates during the process of amino-acid transport into the cytoplasm in E. coli $[8,9]$. In S. flexneri, the function of ArgT has not been elucidated. Given that ArgT expression is dramatically down-regulated at $37^{\circ} \mathrm{C}$ and $\mathrm{S}$. flexneri is phenotypically noninvasive at $30^{\circ} \mathrm{C}$, we presume that the selective expression of $\arg T$ in $S$. flexneri may be related to its virulence. In this study, we confirmed that $\operatorname{argT}$ functions as a novel anti-virulence gene by a competitive invasion assay using $\arg T$ mutations and investigated its mechanism by comparative proteomic analysis.

\section{Materials and methods}

\section{Bacterial strains and growth conditions}

Strain 2457T (our lab) was the wild-type strain of S. flexneri 2 a used throughout this study. There is not much difference in the growth curve of $S$. flexneri 2a 2457T grown at $30^{\circ} \mathrm{C}$ and $37^{\circ} \mathrm{C}$. But the growth speed cultured at $37^{\circ} \mathrm{C}$ is more rapid than at $30^{\circ} \mathrm{C}$. Both the $S$. flexneri 2 a $2457 \mathrm{~T}$ cultured at $30^{\circ} \mathrm{C}$ and $37^{\circ} \mathrm{C}$ grew into early stationary phase with the same $\mathrm{OD}_{600}=2.4$. Strain E. coli DH5 $\alpha$ (our lab) was used for gene cloning, and E. coli BL21 (DE3) (Qiagen, Germany) was used for protein expression. E. coli and S. flexneri strains were grown in LB. When necessary, antibiotics were added at the following concentrations: $50 \mu \mathrm{g}$ of kanamycin/mL or $100 \mu \mathrm{g}$ of ampicillin $/ \mathrm{mL}$.

\section{Construction of the plasmids and strains}

The $\arg T$ genes of $S$. flexneri and $E$. coli were amplified by PCR using primers a1 and a2 (Additional file 1, Table S1) from the $2457 \mathrm{~T}$ and $\mathrm{DH} 5 \alpha$ genomes, respectively. The PCR products were cloned into the pProEX-HTb vector (Invitrogen, USA, Ap ${ }^{\mathrm{r}}$ ) using BamH I and EcoR I sites, generating the pProEX-HTb-argT2457T (ArgT) and pProEX-HTb-argT ${ }^{\mathrm{DH} 5 \alpha}$ (ArgT ${ }^{\mathrm{DH} 5 \alpha}$ ) plasmids. Similarly, $\arg T$ without a signal peptide was amplified with primers a3 and a 2 and ligated into pGEX-6p-2, generating pGEX$6 \mathrm{p}-2-\arg \mathrm{T} 2{ }^{2457 \mathrm{~T}}$ (pGEX-argT2). The $\arg T$ products that included the regulatory region were amplified with primers $\arg \mathrm{TH} 1$ and $\operatorname{argTH} 2$ and cloned into the pAK plasmid [constructed in our lab, using the ori from pACYC184 and kan from pKD4 [10], km ] using BamH I and Sal I sites, generating pAK-argT. To introduce site mutations into $\arg T, \mathrm{PCR}$ was performed with primers containing the desired mutations using the QuikChange SiteDirected Mutagenesis Kit (Stratagene, USA), according to the manufacturer's protocol. The desired site-mutated plasmids $\operatorname{ArgT}_{\mathrm{A} 16 \mathrm{~T}}, \operatorname{ArgT}_{\mathrm{L} 38 \mathrm{P}}, \operatorname{Arg}_{\mathrm{Y} 225 \mathrm{D}}$ and $\mathrm{pAK}-$ $\arg \mathrm{T}_{\mathrm{Y} 225 \mathrm{D}}$ were confirmed by sequencing.

The $\arg T$ deletion mutant of $S$. flexneri (2457T $\Delta \arg T$ ) was constructed by a modified form of lambda red recombination, as described previously [10]. Briefly, 500 bp upstream (a5) and 500 bp downstream (a3) of $\operatorname{argT}$ were independently amplified with the primer pairs a5p1/ $\mathrm{a} 5 \mathrm{p} 2$, and a3p1/a3p2. The products were combined into pET22b (Novagen, Germany, Ap ${ }^{r}$ ) with kan gene. 2457T carrying pKD46 [10] containing the red recombinase genes were grown at $30^{\circ} \mathrm{C}$ in the presence of $10 \mathrm{mM}$ arabinose in order to induce the recombinase genes and then transformed with the gel-purified a5-Kan-a3 PCR products amplified with a5p1 and a3p2 primers. Recombinants were selected from LB plates containing kanamycin. The $\arg T$ rescued strain was constructed by transformation of the pAK-argT plasmid into the $\operatorname{argT}$ deletion strain without the kan gene.

\section{Invasion assays}

To test the virulence alterations in the mutant strains, a competition assay was carried out using a HeLa cells infection model $[11,12]$ or a murine intranasal infection model $[13,14]$ with some modifications. Each assay was repeated three times.

$2457 \mathrm{~T} / \mathrm{pAK}-\arg \mathrm{T}_{\mathrm{Y} 225 \mathrm{D}}$, as well $2457 \mathrm{~T} / \mathrm{pAK}$ and $2457 \mathrm{~T}$ were grown to the early stationary phase, recovered at the same OD values and suspended in normal saline. Cell density was determined by plating. $2457 \mathrm{~T} / \mathrm{pAK}$-arg $\mathrm{T}_{\mathrm{Y} 225 \mathrm{D}}$ and $2457 \mathrm{~T}$ (or $2457 \mathrm{~T} / \mathrm{pAK}$ and $2457 \mathrm{~T}$ ) were mixed at a $1: 1(\mathrm{v} / \mathrm{v})$ ratio, and about $100 \mathrm{MOI}$ of bacteria were allowed to infect HeLa cells in antibiotic-free DMEM at $37^{\circ} \mathrm{C}$ for $4 \mathrm{hrs}$, with three repeats for each group. The cells were then washed with normal saline and fresh DMEM containing gentamicin $(100 \mathrm{ng} / \mathrm{mL})$ was added. After cultivation for another $24 \mathrm{hrs}$, the infected cells were lysed by the addition of $0.1 \%$ deoxycholate sodium to liberate the intracellular bacteria. Dilutions of the lysates were plated on LB plates and cultivated at $37^{\circ} \mathrm{C}$. The next day, colonies were randomly selected from LB plates of each repeat and used to inoculate LB plates with $50 \mu \mathrm{g}$ of kanamycin $/ \mathrm{mL}$. These plates were cultivated at $37^{\circ} \mathrm{C}$ overnight. The number of mutant strains and $2457 \mathrm{~T}$ were then counted. The competitive index was calculated by the method of Camilli et al. [15] according to the formula (mutant number after invasion / wild-type strain number after invasion) / (mutant number before invasion / wild-type strain number before invasion), and student $t$ test was employed to determine the $\mathrm{p}$-value. The invasion assays for the $\arg T$ deletion mutant 2457T $\Delta \arg T$ were performed by the same method.

For the murine intranasal infection, about $10^{6} \mathrm{CFU}$ of mixed bacteria were administered in a total $20 \mu \mathrm{L}$ saline 
split into the nares of $7 \mathrm{BALB} / \mathrm{c}$ mice. After $24 \mathrm{hrs}$, the bacteria recovered from the lungs of the mice were treated by the method described above, and the competitive index of each mutant was calculated.

\section{Comparative proteomic analysis}

The preparation of whole-cell protein extracts from different $2457 \mathrm{~T}$ strains cultured at $37^{\circ} \mathrm{C}$ or $30^{\circ} \mathrm{C}$ was performed as described previously [16]. The protein concentration of each sample was measured using the PlusOne 2-D Quant Kit (GE Healthcare, USA). The samples with $800 \mu \mathrm{g}$ proteins were then treated with a 2-D Clean-Up Kit (GE Healthcare) and suspended in $350 \mu \mathrm{L}$ rehydration buffer (7 M Urea, $2 \mathrm{M}$ Thiourea, 4\% CHAPS, $50 \mathrm{mM}$ DTT, 0.5\% IPG Buffer). IEF was performed by using $\mathrm{pH} 4-7$ and $\mathrm{pH}$ 6-11 IPG strips $(18 \mathrm{~cm}$, GE Healthcare) to obtain better separation and more spots at $20^{\circ} \mathrm{C}$ for $60,000 \mathrm{~V} \cdot \mathrm{h}$. After IEF, each strip was equilibrated. For the second dimension, vertical slab SDS-PAGE (12.5\%) was performed for about $4.5 \mathrm{hrs}$ at $30 \mathrm{~mA} /$ gel by using a Bio-Rad Protean II Xi apparatus (Bio-Rad, Hercules, USA). A biological replicate at least 3 times involved in the gels running. When using the DIGE (differential ingel electrophoresis) technique, $50 \mu \mathrm{g}$ proteins from each temperature were covalently labeled with a fluorescent dye, either cy5 or cy3 (GE Healthcare), mixed equally, and then separated by 2-DE. The image gel was scanned using a 633-nm laser for cy5 or a 543-nm laser for cy3. The entire DIGE process was protected from light. Image analysis was processed by DeCyder-DIA software for the DIGE profiles and ImageMaster 2D Platinum software for common 2-DE profiles (GE Healthcare).

The protein spots of interest were cut out, and in-gel protein digestion was performed as described previously [16]. Peptides from digested proteins were resolubilized in $2 \mu \mathrm{L}$ of $0.5 \%$ triflouroacetic acid (TFA). The MALDITOF-MS measurement was performed on a Bruker Reflex III MALDI-TOF-MS (Bruker Daltonics, Germany) operating in reflectron mode with a $20 \mathrm{kV}$ accelerating voltage and a $23 \mathrm{kV}$ reflecting voltage. A saturated solution of $\alpha$-cyano-4-hydroxycinnamic acid in $50 \%$ acetonitrile and $0.1 \%$ trifluoroactic acid was used as the matrix. One microliter of a 1:1 mixture of the matrix solution and sample solution was loaded into the Score384 target well. Mass accuracy for peptide mass fingerprint (PMF) analysis was calibrated using a 0.1 Da-0.2 Da external standard, and internal calibration was carried out with enzyme autolysis peaks at a resolution of 12,000. PMFs were identified using the Mascot program (Matrix Science Ltd, UK) by searching a proprietary S. flexneri 2 a $2457 \mathrm{~T}$ database, and the results were checked against the NCBInr public database. Monoisotopic masses were used to search the databases, allowing a peptide mass accuracy of $0.3 \mathrm{Da}$ and one partial cleavage. Oxidation of methion- ine and carbamidomethyl modification of cysteine was considered. For unambiguous identification of proteins by MALDI-TOF data, the constraint of a match of five or more peptides was applied.

\section{Protein purification and antibody production}

The expression of fusion proteins was induced by adding $1 \mathrm{mM}$ IPTG when cultures were grown to an $\mathrm{OD}_{600}$ of 0.6-0.9 at $30^{\circ} \mathrm{C}$, after which they were continuously cultured for another $16 \mathrm{hrs}$ at $20^{\circ} \mathrm{C}$. The induced ArgT fusion protein was purified from the cultures using Glutathione Sepharose 4B beads (Amersham, UK). The purified GST-ArgT proteins were injected subcutaneously into each of two BALB/c female mice to generate polyclonal ArgT antibody. Sera from the immunized mice were collected and purified by affinity chromatography, according to the manufacturer's instructions (Pierce, USA).

\section{SDS-PAGE and Western-blot analysis}

Samples were boiled and loaded onto 12\% SDS-PAGE gels [17]. After electrophoresis, proteins were transferred to PVDF membranes (Immobilon-Millipore, USA) and blocked with $5 \%$ nonfat milk. Both incubations with primary antibody diluted 1:5000 and secondary antibody conjugated to horseradish peroxidase (Santa Cruz Biotechnology, USA) diluted 1:10000 in blocking buffer were performed for $1 \mathrm{~h}$ at room temperature. Immunoblots were washed three times with Tris-buffered saline containing $0.05 \%$ Tween 20 after both antibody incubations. The ECL Plus kit (Pierce) was used for detection.

\section{Results}

\section{ArgT expression down-regulated at $37^{\circ} \mathrm{C}$ by DIGE analysis}

The DIGE profiles of $2457 \mathrm{~T}$ grown to early stationary growth phase at $30^{\circ} \mathrm{C}$ and $37^{\circ} \mathrm{C}$ showed the proteins expressed at the two temperatures were very similar. A total of 922 spots were detected in the DIGE profile. A protein was considered to be temperature-dependent if the spot density was significantly different (two-fold or greater) under the two temperature conditions. Each differentially expressed spot was selected for identification by MALDI-TOF-MS. Among these differential spots, the abundance of ArgT was dramatically decreased at $37^{\circ} \mathrm{C}$ (Fig. 1), which was in contrast to the general virulence factors whose abundances were increased at $37^{\circ} \mathrm{C}$. The expression amount of $\mathrm{ArgT}$ at $30^{\circ} \mathrm{C}$ is about 27 fold more than that at $37^{\circ} \mathrm{C}$. However, The quantities of $\operatorname{argT}$ mRNA under the two temperatures were similar according to the results of real-time PCR (the mRNA abundance in $30^{\circ} \mathrm{C}$ is about $2^{0.58}=1.49$ fold more than that in $37^{\circ} \mathrm{C}$ )(Data not shown). Based upon this observation, we next wanted to determine if ArgT was related to the virulence of $S$. flexneri. 


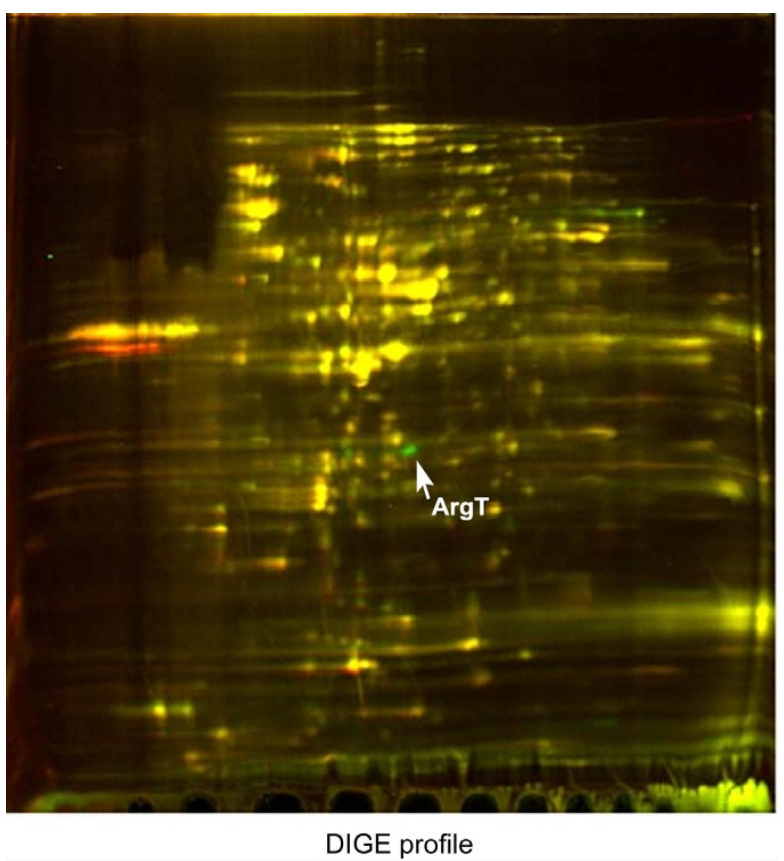

Figure 1 DIGE profile of S. flexneri. The green spots represent proteins up-regulated at $30^{\circ} \mathrm{C}$, the red spots represent proteins up-regulated at $37^{\circ} \mathrm{C}$, and the yellow spots represent proteins without obvious differences between the two temperature conditions.

\section{ArgT expression rescued by a single amino-acid residue site} mutation in S. flexneri argT

Protein ArgT of 2457T had been demonstrated to be a periplasmic protein in our previous work [7]. If the significantly differential expression of ArgT was related to the virulence of $S$. flexneri, this phenomenon should not occur in its non-pathogenic ancestor (E. coli). Thus, the $\arg T$ gene from E. coli DH5 $\alpha$ was cloned and overexpressed in both $2457 \mathrm{~T}$ and DH5 $\alpha$. Regardless of the incubation temperature, the expression of E. coli ArgT can be detected in DH5 $\alpha$ and 2457T (Fig. 2A). The different fates of S. flexneri and E. coli ArgT suggested that the sequence of the $S$. flexneri $\arg T$ gene may have changed, endowing a survival advantage over its non-pathogenic ancestor during the long evolutionary process.

The expression product of $\arg T$ in $S$. flexneri shares a $98.85 \%$ identity with its counterpart in E. coli. Comparison of the ArgT sequences of $2457 \mathrm{~T}$ and DH5 $\alpha$ revealed that there were only three amino acid changes, which were A16T, L38P and Y225D (Fig. 2B). These three amino acids in the S. flexneri ArgT were site-mutated into the corresponding E. coli ArgT amino acids to generate three different expression vectors $\left(\mathrm{ArgT}_{\mathrm{A} 16 \mathrm{~T}}, \mathrm{ArgT}_{\mathrm{L} 38 \mathrm{P}}\right.$ and $\left.\operatorname{ArgT}_{\mathrm{Y} 225 \mathrm{D}}\right)$. The expression of ArgT in 2457T carrying $\operatorname{ArgT}_{\mathrm{A} 16 \mathrm{~T}}$ or $\operatorname{ArgT}_{\mathrm{L} 38 \mathrm{P}}$ did not differ from that of the wild type, which indicated that the mutation of Ala into Thr or of Leu into Pro at these sites had no effect on the expres- sion of ArgT. In contrast, the mutation of Tyr255 into Asp could rescue the expression of $\mathrm{ArgT}$ at $37^{\circ} \mathrm{C}$ (Fig. 2C). Since ArgT regulation has been demonstrated to be a posttranslational proteolysis event [7], the Tyr at the 225 position might be a key amino acid residue that is involved in the regulation, whose change renders the protein less susceptible to proteolytic attack.

The virulence of 2457T attenuated by ArgT over-expression To test the virulence-related function of $\arg T$, $\arg T$ deletion and over-expression strains were constructed and used for an invasion assay. The $\arg T$ deletion mutant was confirmed by PCR with the internal primers, external primers and kan primers (Fig. 3A), and the ArgT overexpression strain was detected by SDS-PAGE and Western blotting (Fig. 3B). Here, a recombinant strain carrying the low-copy expression vector $\mathrm{pAK}$-argT $\mathrm{T}_{\mathrm{Y} 225 \mathrm{D}}$ (containing the $\arg T$ of $2457 \mathrm{~T}$ with the native regulatory region but mutated at position 225) was used as the ArgT overexpression strain to better simulate the state of the $\operatorname{argT}$ gene in vivo. The competitive invasion assays in HeLa cells and BALB/c mice by argT deletion and over-expression strains were performed in triplicate. Since the virulence could not be changed by argT deletion in our initial assay, the $\arg T$ deletion strain was not used in the later mice invasion assays. The competitive index (CI) was calculated and is shown in Figs. 3C and 3D. From these data, we concluded that $\arg T$ deletion had no impact on the virulence of $2457 \mathrm{~T}$; however, ArgT over-expression attenuated the virulence at $37^{\circ} \mathrm{C}$.

\section{Differentially expressed proteins in the comparative proteomic analysis}

In addition to confirming the above hypothesis that ArgT depresses the virulence of $S$. flexneri by invasion assay, we also searched for clues of the mechanism at the molecular level by comparative proteomic analysis. The protein expression profiles of wild-type 2457T, the $\arg T$ deletion mutant and the ArgT over-expression strain at $37^{\circ} \mathrm{C}$ are shown in Fig. 4. The 2-DE profiles of different $\operatorname{argT}$ mutants were compared with the wild-type 2457T, and they were highly comparable. Only eight spots with expression level differences greater than two-fold were excised for further analysis (Additional file 1, Table S2). Since there is no obvious difference in growth curve and biochemical reactions tested by API strips (data not shown) between the wild strain and its derivative strains, we concluded that the change in protein expression was not caused by manipulation.

The differential protein expression between the $\operatorname{argT}$ mutant and wild-type strains might be related to the function of ArgT. Among the differentially expressed proteins, HtrA attracted our attention because of its potential function as a virulence factor [18]. The expression of 


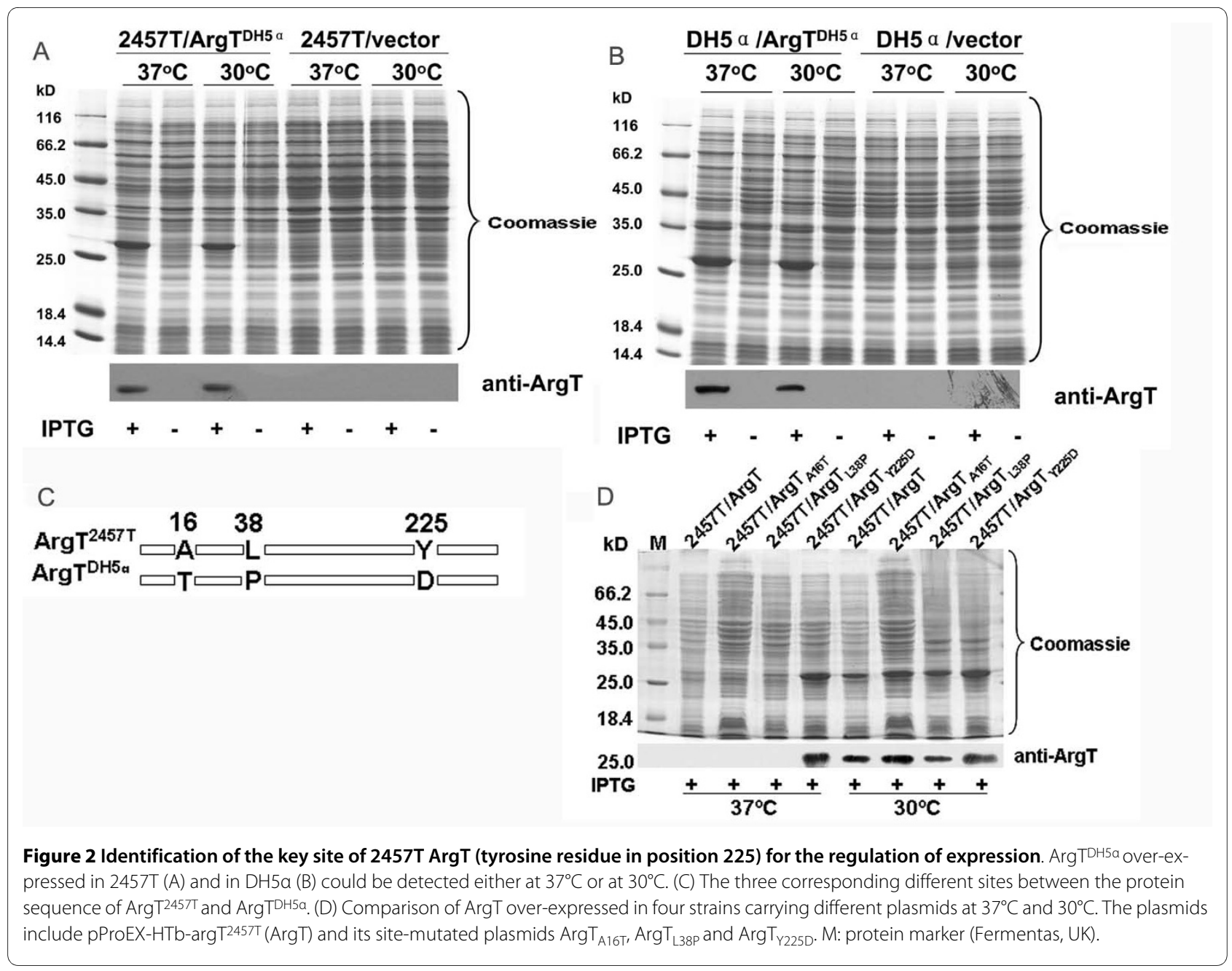

HtrA varied with the different expression levels of ArgT. Two spots were identified as HtrA in the wild-type strains, and the abundance of the left was higher than the right (Fig. 4). When $\arg T$ was deleted, however, the abundance of the right spot was higher than the left. Only the left spot was detectable in the ArgT over-expression strain. However, separation of large proteins at high pI regions is more susceptible. We will do further study to verify the reliability of this phenomenon in the next work.

\section{Discussion}

Comparative analysis of virulence potential is a cornerstone in understanding the ability of a pathogen to cause disease and in determining the relative contribution of putative virulence factors. Using this method, we found that ArgT over-expression could attenuate the virulence at $37^{\circ} \mathrm{C}$. This result was consistent with that of the comparative proteomic analysis of $2457 \mathrm{~T}$ at $37^{\circ} \mathrm{C}$ and $30^{\circ} \mathrm{C}$, in which ArgT was normally expressed when $2457 \mathrm{~T}$ was noninvasive but not required when $2457 \mathrm{~T}$ was invasive. In addition, we showed that $2457 \mathrm{~T}$ ArgT disappeared at $37^{\circ} \mathrm{C}$, while $\mathrm{DH} 5 \alpha$ ArgT could be detected at $37^{\circ} \mathrm{C}$. These observations are in line with the criteria for the identification of anti-virulence genes that were proposed by Dr. Maurelli: 1) anti-virulence genes are present and expressed in E. coli but deleted or mutated in S. flexneri; and 2) their compulsive expression in S. flexneri can attenuate virulence [5].

Bacterial pathogens can either acquire virulence genes or lose anti-virulence genes through horizontal gene transfer during their evolution, and examination of the latter has just begun in recent years [5]. Selective pressure can lead to the deletion or inactivation of genes that are no longer compatible with the lifestyle of the pathogen. A few examples include $\operatorname{cad} A, \operatorname{omp} T$, $\operatorname{nad} A$ and $\operatorname{nad} B[5,6]$, which are all absent or inactive in $S$. flexneri but present and expressed in the non-virulent ancestral $E$. coli. The expression of any of these genes in the pathogen would be adverse to the expression of virulence genes [5]. In this case, $\arg T$, which has been identified as a novel anti-virulence gene, is not totally absent in S. flexneri. Instead, it is expressed at $30^{\circ} \mathrm{C}$. One potential explanation could be 


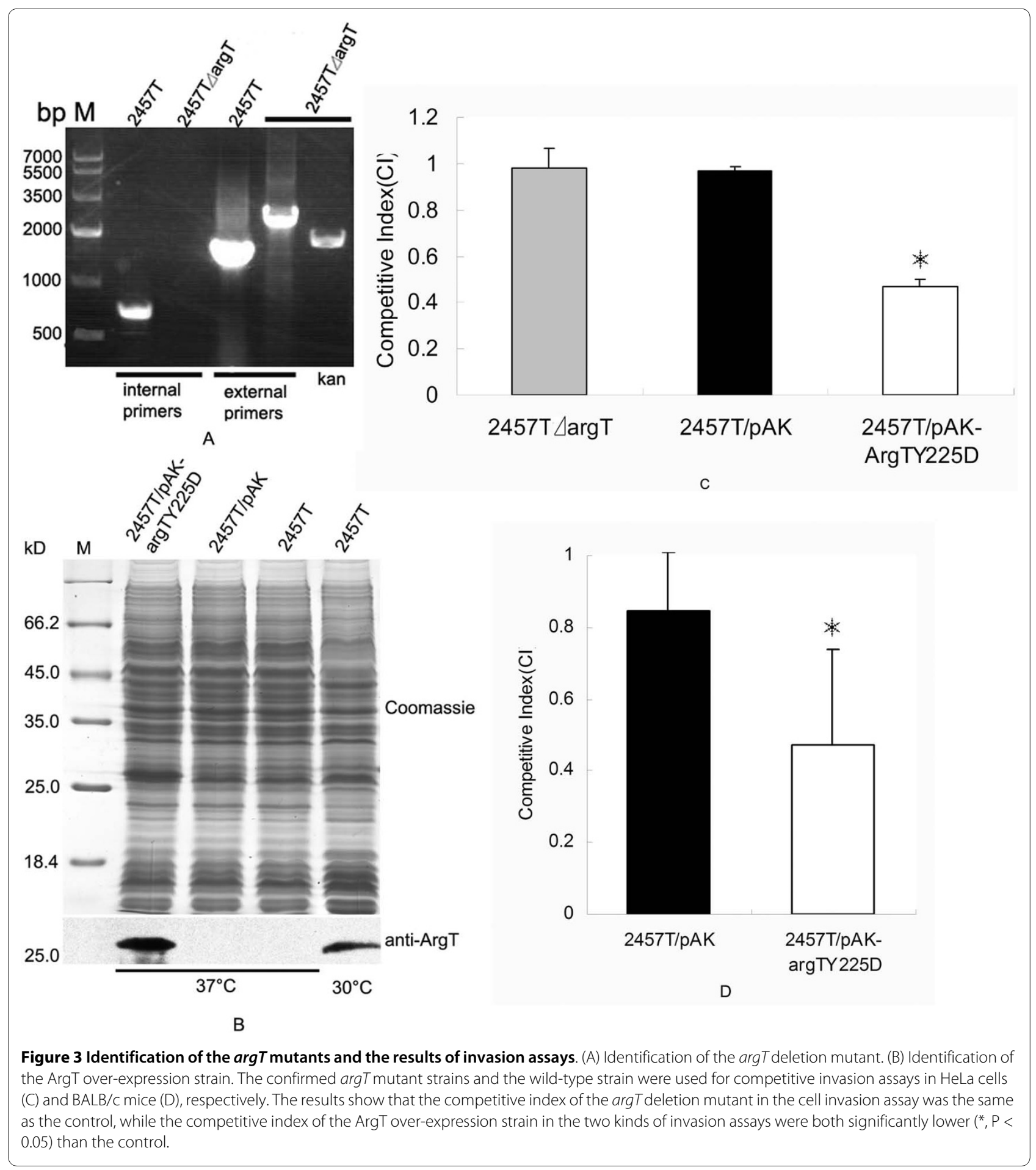

that its role in amino acid transport facilitates the survival of S. flexneri in non-host environments and, thus, provides a selective advantage for those cells that harbor this gene.

Although ArgT may be a novel anti-virulence gene, the mechanism by which ArgT interferes with the invasion of S. flexneri remains unknown. One possibility could be that the amino acids that are transported by ArgT depress the virulence. For example, lysine could be decarboxylated to cadaverine by lysine decarboxylase, and the latter could block the ability of $S$. flexneri to elicit transepithelial migration of polymorphonuclear neutrophils for the inflammatory response [19]. If this possibility exists, there must be a new virulence inhibitor other than cadav- 


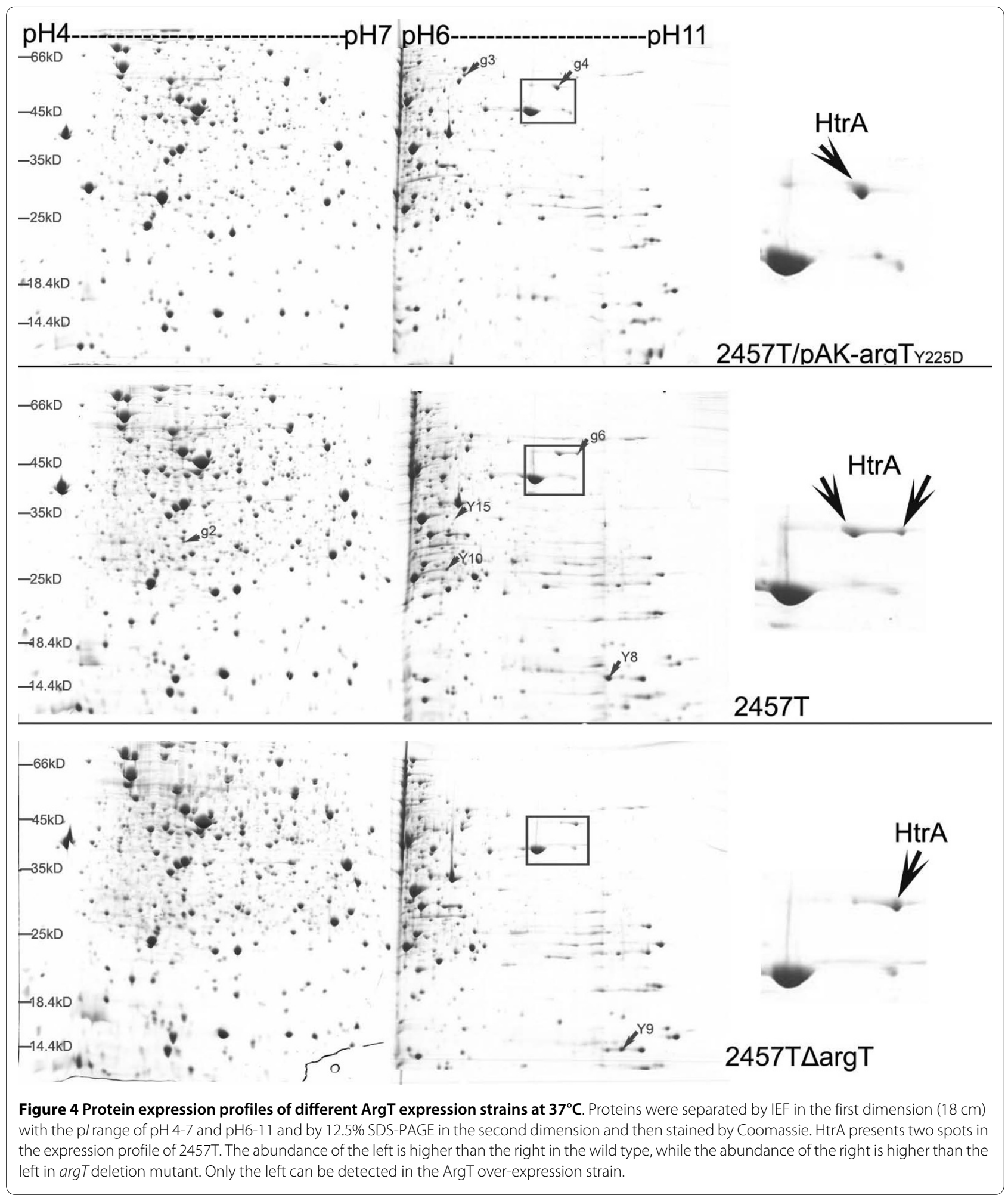

erine, because the gene encoding lysine decarboxylase $(\operatorname{cad} A)$ has been deleted in the genome of S. flexneri. In addition, ornithine, in conjunction with uracil, has been reported to significantly reduce the hemolytic ability of wild-type cultures and the expression of the type III secretion system [20]. Another possibility could be related to HtrA, whose expression was varied with the different expression levels of ArgT. HtrA is a periplasmic protease that participates in the processing or modification of surface proteins and the degradation of abnormal 
or incorrectly folded proteins [21]. Here, however, we were more interested in the virulence-related function of HtrA. HtrA has been reported to facilitate the surface expression of IcsA and is required for the efficient intercellular spread of S. flexneri [22]. HtrA has also been found to be a virulence factor in other bacteria, such as Salmonella typhimurium [23] and Listeria monocytogenes [24]. In this study, the two spots (left and right) of HtrA in the proteomic profile might correspond to two different modified forms and the right form might be related to virulence due to its presence in strains with invasive ability. Since ArgT of $2457 \mathrm{~T}$ has been demonstrated to be located in periplasm [7], and HtrA is also a periplasmic protein in S. flexneri, the two proteins must interact with each other directly or indirectly. We suggested that, if ArgT could not be degraded by HtrA, as $\operatorname{ArgT}_{\text {Y225D }}$ did, it might influence the modification of HtrA, which would subsequently influence the virulence of S. flexneri. The putative mechanism by which this modification occurs and interferes with virulence will require further study.

Besides HtrA, some other proteins such as OmpA and PepA showed differential expression in the derived 2457T strains. OmpA is an outer membrane protein, which can function as an adhesion and invasion, participate in biofilm formation, act as both an immune target and evasion, and serves as a receptor for several bacteriophages [25]. Here, OmpA is down-regulated expression in ArgT over-expression $2457 \mathrm{~T}$ strains, and the virulence of this strain is decreased, these phenomena just manifested that OmpA is a potential virulence factor in $2457 \mathrm{~T}$ due to its adhesion and invasion functions. PepA is a leucyl aminopeptidase, and no reports mentioned that PepA was involved in virulence, so here its up-regulated expression in ArgT over-expression 2457T strains may be related to the amino acid metabolism due to the amino-acid transportation function of ArgT.

Anti-virulence genes provide us with new insights into the ecology and evolution of bacterial pathogens. The study of anti-virulence genes holds the potential for discovery of new pathogen-specific therapies and the development of safer, attenuated vaccine strains. How could we find anti-virulence genes? Traditional methods that focus on laboratory phenotypes have been proven successful but laborious. The comparative genomic strategies that exploit data provided by genome sequencing studies are well accepted for the identification of anti-virulence genes. However, those anti-virulence genes still present in the genome of pathogens like $\arg T$ can not be identified through genomic analysis. Comparative proteomics is one of the best supplemental approaches. Since proteins are the functional output of genes, analysis of the changes in proteome of pathogens grown at conditions similar to their host environments will uncover those precisely regulated and selectively expressed genes.
So, it's reasonable that comparative proteomics will eventually become another powerful tool to discover additional anti-virulence genes in this post-genome era.

\section{Conclusion}

ArgT functions as an anti-virulence factor that potentially interferes with the invasion ability of S. flexneri either through the transportation of specific amino acids or by an influence on the expression of the virulence factor HtrA.

\section{Additional material}

Additional file 1 Table S1 - Primers used in this study and Table S2

Identification of 8 differential-expression proteins by MALDI-TOF MS between argT mutants and wild-type strain.

\section{Abbreviations}

DIGE: differential in-gel electrophoresis; TTSS: type III secretion system; LAO: lysine/arginine/ornithine-binding protein; 2-DE: Two-dimensional Polyacrylamide Gel Electrophoresis; MALDI-TOF-MS: matrix-assisted laser desorption ionisation- time of flight-mass spectrometry; PMF: peptide mass fingerprint; $\mathrm{Cl}$ : competitive index.

\section{Competing interests}

The authors declare that they have no competing interests.

\section{Authors' contributions}

GZ and XYC performed the mutants construction and invasion assay experiments. LZ, XL and TYY carried out the 2-D PAGE experiments. ELF and XKL conducted the database search and bioinformatics analyses. JW operated the MALDI-TOF MS instrument and calibrated all of the original MS data. NS performed Western Blotting analysis. GZ, LZ and HLW were responsible for data analysis and drafting the manuscript. HPC and HLW participated in the study design and helped to draft the manuscript. All authors read and approved the final manuscript.

\section{Acknowledgements}

We are grateful to Dr. Helen Zhang for her corrections of grammatical or stylistic errors in this paper. This work was supported by the National Key Basic Research Program of China (973 Program, No. 2005CB522904) and the National Natural Science Foundation of China (No. 30470101 and No. 30700035).

\section{Author Details}

1Beijing Institute of Biotechnology, State Key Laboratory of Pathogen and Biosecurity, Beijing 100071, China, 2Shandong Eye Institute, Qingdao 266071 China and ${ }^{3}$ National Center of Biomedical Analysis, Beijing 100850, China

Received: 9 December 2009 Accepted: 12 June 2010

Published: 12 June 2010

\section{References}

1. Le Gall T, Mavris M, Martino MC, Bernardini ML, Denamur E, Parsot C Analysis of virulence plasmid gene expression defines three classes of effectors in the type III secretion system of Shigella flexneri. Microbiology 2005, 151:951-962.

2. Maurelli AT, Blackmon B, Curtiss R: Temperature-dependent expression of virulence genes in Shigella species. Infect Immun 1984, 43:195-201.

3. Beloin C, Dorman CJ: An extended role for the nucleoid structuring protein $\mathrm{H}-\mathrm{NS}$ in the virulence gene regulatory cascade of Shigella flexneri. Mol Microbiol 2003, 47:825-838.

4. Lee CA: Pathogenicity islands and the evolution of bacterial pathogens. Infect Agents Dis 1996, 5:1-7

5. Maurelli AT: Black holes, antivirulence genes, and gene inactivation in the evolution of bacterial pathogens. FEMS Microbio/ Lett 2007, 267:1-8.

6. Prunier AL, Schuch R, Fernandez RE, Mumy KL, Kohler H, McCormick BA, Maurelli AT: nadA and nadB of Shigella flexneri $5 a$ are antivirulence loci 
responsible for the synthesis of quinolinate, a small molecule inhibitor of Shigella pathogenicity. Microbiology 2007, 153:2363-2372.

7. Zhu L, Zhao G, Stein R, Zheng X, Hu W, Shang N, Bu X, Liu X, Wang J, Feng E, Zhang X, Ye Q, Huang P, Zeng M, Wang H: The proteome of Shigella flexneri 2a $2457 \mathrm{~T}$ grown at $30^{\circ} \mathrm{C}$ and $37^{\circ} \mathrm{C}$. Mol Cell Proteomics 2010. Paper in press, PMID: 20164057

8. Celis TF, Rosenfeld HJ, Maas WK: Mutant of Escherichia coli K-12 defective in the transport of basic amino acids. J Bacteriol 1973, 116:619-626.

9. Rosen BP: Basic amino acid transport in Escherichia coli. J Biol Chem 1971, 246:3653-3662.

10. Datsenko KA, Wanner BL: One-step inactivation of chromosomal genes in Escherichia coli K-12 using PCR products. Proc Natl Acad Sci USA 2000, 97:6640-6645.

11. Sizemore DR, Branstrom AA, Sadoff JC: Attenuated Shigella as a DNA delivery vehicle for DNA-mediated immunization. Science 1995, 270:299-302.

12. Shi $Z X$, Wang HL, Hu K, Feng EL, Yao X, Su GF, Huang PT, Huang LY: Identification of alkA gene related to virulence of Shigella flexneri $2 \mathrm{a}$ by mutational analysis. World J Gastroentero/ 2003, 9:2720-2725.

13. Way SS, Sallustio S, Magliozzo RS, Goldberg MB: Impact of either elevated or decreased levels of cytochrome bd expression on Shigella flexneri virulence. J Bacterio/ 1999, 181:1229-1237.

14. van de Verg LL, Mallett CP, Collins HH, Larsen T, Hammack C, Hale TL: Antibody and cytokine responses in a mouse pulmonary model of Shigella flexneri serotype 2a infection. Infect Immun 1995, 63:1947-1954

15. Camilli A, Mekalanos JJ: Use of recombinase gene fusions to identify Vibrio cholerae genes induced during infection. Mol Microbiol 1995 18:671-683.

16. Ying T, Wang H, Li M, Wang J, Shi Z, Feng E, Liu X, Su G, Wei K, Zhang X Huang $P$, Huang $L:$ Immunoproteomics of outer membrane proteins and extracellular proteins of Shigella flexneri 2a 2457T. Proteomics 2005, 5:4777-4793.

17. Laemmli UK: Cleavage of structural proteins during the assembly of the head of bacteriophage T4. Nature 1970, 227:680-685.

18. Pallen MJ, Wren BW: The HtrA family of serine proteases. Mol Microbiol 1997, 26:209-221.

19. McCormick BA, Fernandez MI, Siber AM, Maurelli AT: Inhibition of Shigella flexneri-induced transepithelial migration of polymorphonuclear leucocytes by cadaverine. Cell Microbiol 1999, 1:143-155.

20. Durand JM, Bjork GR: Metabolic control through ornithine and uracil of epithelial cell invasion by Shigella flexneri. Microbiology 2009, 155:2498-2508

21. Biswas S, Biswas I: Role of HtrA in surface protein expression and biofilm formation by Streptococcus mutans. Infect Immun 2005, 73:6923-6934.

22. Purdy GE, Hong M, Payne SM: Shigella flexneri DegP facilitates IcsA surface expression and is required for efficient intercellular spread. Infect Immun 2002, 70:6355-6364.

23. Baumler AJ, Kusters JG, Stojiljkovic I, Heffron F: Salmonella typhimurium loci involved in survival within macrophages. Infect Immun 1994, 62:1623-1630

24. Stack HM, Sleator RD, Bowers M, Hill C, Gahan CG: Role for HtrA in stress induction and virulence potential in Listeria monocytogenes. App/ Environ Microbiol 2005, 71:4241-4247.

25. Smith SG, Mahon V, Lambert MA, Fagan RP: A molecular Swiss army knife: OmpA structure, function and expression. FEMS Microbiol Lett 2007, 273:1-11.

doi: $10.1186 / 1477-5956-8-30$

Cite this article as: Zhao et al., A novel anti-virulence gene revealed by proteomic analysis in Shigella flexneri 2a Proteome Science 2010, 8:30

\section{Submit your next manuscript to BioMed Central} and take full advantage of:

- Convenient online submission

- Thorough peer review

- No space constraints or color figure charges

- Immediate publication on acceptance

- Inclusion in PubMed, CAS, Scopus and Google Scholar

- Research which is freely available for redistribution

Submit your manuscript at www.biomedcentral.com/submit
C Biomed Central 